\title{
UAV/SATELLITE MULTISCALE DATA FUSION FOR CROP MONITORING AND EARLY STRESS DETECTION
}

\author{
V. Sagan ${ }^{1, *}$, M. Maimaitijiang ${ }^{1}$, P. Sidike ${ }^{1}$, M. Maimaitiyiming ${ }^{1}$, \\ H. Erkbol ${ }^{1}$, S. Hartling ${ }^{1}$, K.T. Peterson ${ }^{1}$, J. Peterson ${ }^{2}$, J. Burken ${ }^{3}$, F. Fritschi ${ }^{4}$ \\ ${ }^{1}$ Department of Earth and Atmospheric Sciences, Saint Louis University, Saint Louis, MO 63108, USA \\ - (vasit.sagan, mason.maimaitijiang, sidike.paheding, matt.maimaitiyiming, \\ aishanjiang.yasen, sean.hartling, kyle.t.peterson)@slu.edu \\ ${ }^{2}$ Department of Technology \& Construction Management, Missouri State University, \\ Springfield, MO 65897, USA - jimpeterson@missouristate.edu \\ ${ }^{3}$ Department of Civil, Architectural and Environmental Engineering, MS\&T, \\ Rolla, MO 65409, USA - burken@mst.edu \\ ${ }^{4}$ Division of Plant Sciences, University of Missouri, Columbia, MO 65211, USA - fritschif@ missouri.edu
}

KEY WORDS: Data Fusion, UAV, Crop Monitoring, Stress Detection

\begin{abstract}
:
Early stress detection is critical for proactive field management and terminal yield prediction, and can aid policy making for improved food security in the context of climate change and population growth. Field surveys for crop monitoring are destructive, labor-intensive, time-consuming and not ideal for large-scale spatial and temporal monitoring. Recent technological advances in Unmanned Aerial Vehicle (UAV) and high-resolution satellite imaging with frequent revisit time have proliferated the applications of this emerging new technology in precision agriculture to address food security challenges from regional to global scales. In this paper, we present a concept of UAV and satellite virtual constellation to demonstrate the power of multi-scale imaging for crop monitoring. Low-cost sensors integrated on a UAV were used to collect RGB, multispectral, and thermal images during the growing season in a test site established near Columbia, Missouri, USA. WorldView-3 multispectral data were pan-sharpened, atmospherically corrected to reflectance and combined with UAV data for temporal monitoring of early stress. UAV thermal and multispectral data were calibrated to canopy temperature and reflectance following a rigorous georeferencing and ortho-correction. The results show that early stress can be effectively detected using multi-temporal and multi-scale UAV and satellite observation; the limitations of satellite remote sensing data in field-level crop monitoring can be overcome by using low altitude UAV observations addressing not just mixed pixel issues but also filling the temporal gap in satellite data availability enabling capture of early stress. The concept developed in this paper also provides a framework for accurate and robust estimation of plant traits and grain yield and delivers valuable insight for high spatial precision in high-throughput phenotyping and farm field management.
\end{abstract}

\section{INTRODUCTION}

Changes in precipitation patterns and temperature variability due to climate change are expected for many parts of the world, threatening global food security and resulting in tens of billions of dollars in crop damage. Best farming strategies should focus on early detection of water stress so that decisions on preventive measures can be made in a timely manner.

Field surveys have been used extensively for agricultural management, but they are destructive, labor-intensive, time-consuming and not ideal for large-scale spatial and temporal monitoring. Satellite remote sensing has been used widely for vegetation water stress detection (Kogan, 1995, Seguin et al., 1991) utilizing a broad spectrum of visible and near infrared (VNIR) (Ghulam et al., 2008), thermal infrared (Anderson et al., 2012, Han et al., 2016, Sagan et al., 2019) to microwaves (Chakraborty et al., 2016, Steele-Dunne et al., 2017). However, several limitations exist with current satellite platforms for agricultural and crop physiology monitoring primarily due to coarser ground sampling distance (GSD) and insufficient revisit frequency which are not suitable for field-level studies (Sagan et al., 2019). Detailed monitoring crop physiology may require near daily revisits to

\footnotetext{
${ }^{*}$ Corresponding author
}

accurately monitor physiological changes that are dependent on atmospheric conditions such as rainfall and temperature. Furthermore, plant physiology changes on a cyclical diurnal nature based on photosynthetic activity and processes dependent on incident solar radiation. Current satellite sensors with sufficient temporal revisit time (i.e. MODIS, Sentinel-3, etc.) of about one day lack the fine spatial resolution required for local scale monitoring rang in GSDs from 250-500m. Given this coarse spatial resolution, issues arise due to spectral mixing between soil, crops, and surrounding areas that degrade the spectral purity and hinder modeling efforts (Damm et al., 2018). While moderate resolution satellites such as Landsat- 8 and Sentinel-2 provide sufficient spatial resolution to combat mixed pixels and spectral uncertainty they lack temporal resolution with revisit times of about 8-16 days, which is not ideal for capturing key phenological developments or detection of early stress. As a precursor to impending drought, failure to detect early stress may result in advancing stress beyond recovery, causing a large-scale vegetation dieback and community shifts.

Unmanned Aerial Vehicle (UAV)-based monitoring systems serve as an ideal solution for field-scale crop monitoring providing high spatial and temporal revisit times necessary to capture plant physiological changes. Although UAV-based 


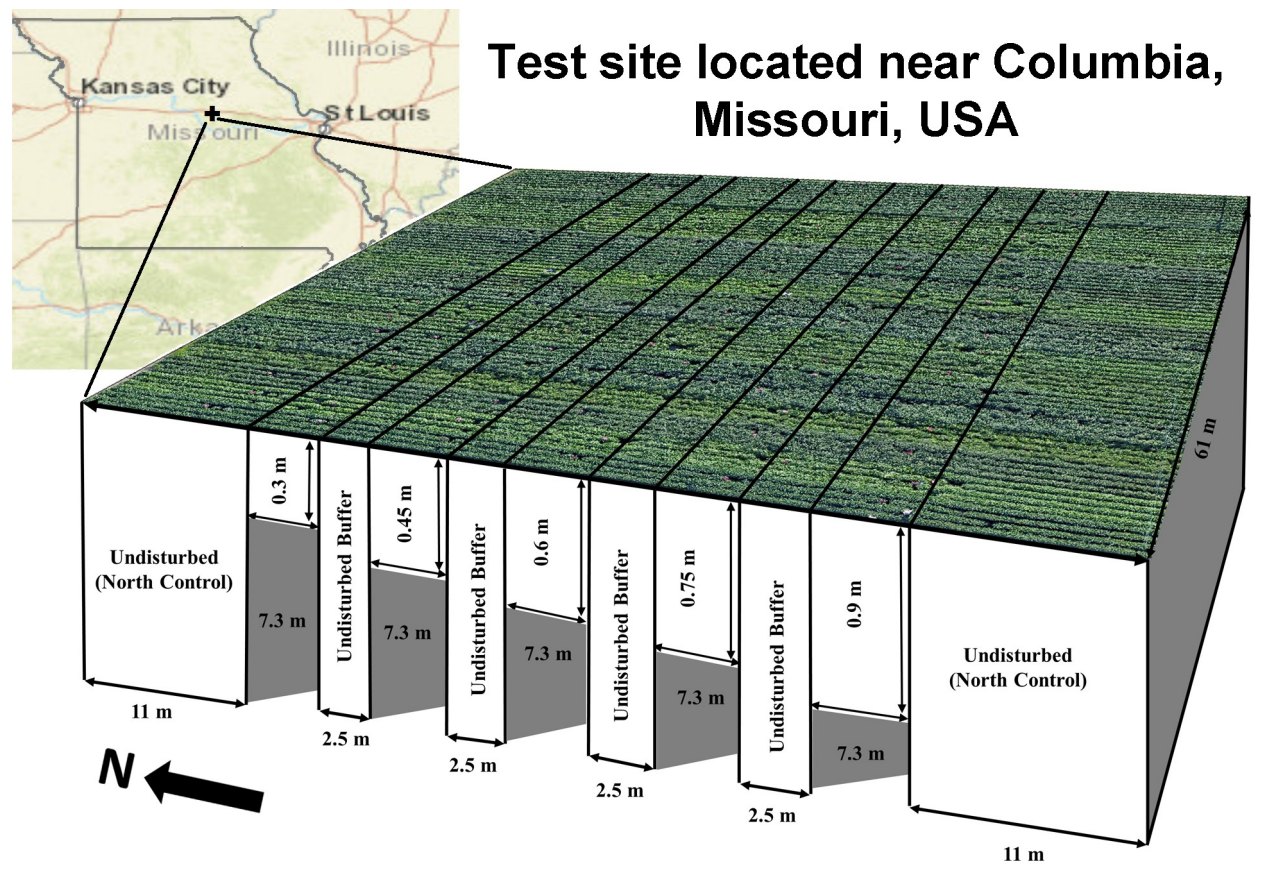

Figure 1. Test site location and UAV-based RGB imagery captured by Mavic Pro with restricting plant roots to different depth and undisturbed areas along with north-south orientation as well as between rooting depth treatments. The figure was modified after (Hoyos-Villegas et al. 2014, Sagan et al. 2019).

remote sensing is limited in its ability for large-scale monitoring, it is becoming a precondition for satellite remote sensing with its capability to build and test field-scale models that can be scaled to regional and global scales by translating UAV-based models to satellite observations. Recent technological advances in UAV platform and sensor technology and high-resolution satellite imaging (e.g., WorldView constellation and Plant Scope) are expanding the applications of this emerging new technology in precision agriculture to address food security challenges globally.

The objectives of this paper were to demonstrate the concept of temporal data fusion in the context of UAV and satellite virtual consultation to estimate pre-visual indicators of crop water stress. Both multi-day satellite images and diurnal UAV datasets were collected over an open agricultural experimental site located near Columbia, Missouri, USA in the growing season of 2017. Early stress developments and recovery was analyzed using WorldView-3 and UAV datasets.

\section{STUDY AREA AND DATA}

\subsection{Study site}

The study area is located at the University of Missouri Bradford Research Center near Columbia, Missouri, USA (Latitude $43^{\circ} 05^{\prime} 30^{\prime \prime} N$, Longitude $56^{\circ} 92^{\prime} 24^{\prime \prime} E$ ) within the continental humid climate zone. Measured by an on-site weather station, the average monthly growing season temperature and precipitation were $17.4^{\circ} \mathrm{C} / 114 \mathrm{~mm}$ in May, $22.6^{\circ} \mathrm{C} / 82 \mathrm{~mm}$ in June, $25.0^{\circ} \mathrm{C} / 116 \mathrm{~mm}$ in July, $21.0^{\circ} \mathrm{C} / 77 \mathrm{~mm}$ in August, $20.2^{\circ} \mathrm{C} / 20 \mathrm{~mm}$ in September, and $13.8^{\circ} \mathrm{C} / 98 \mathrm{~mm}$ in October (Maimaitijiang et al., 2019).

Based on a randomized entry location with four replications, the experimental field, which was approximately $61 \mathrm{~m}$ wide and 77 $\mathrm{m}$ long, was excavated perpendicular to the length of the field to $0.3 \mathrm{~m}, 0.45 \mathrm{~m}, 0.6 \mathrm{~m}, 0.75 \mathrm{~m}$, and $0.9 \mathrm{~m}$ depths at which a plastic barrier was placed to limit rooting depth prior to refilling the excavated channels (Figure 1). Between each of the rooting depth treatments, the soil profile was not disturbed in order to represent normal field conditions at this site. Experimental factors were controlled, including weed control applied in advance of soybean (Glycine max) planting on 18 April 2017. No insect or pest control was required. Five soybean genotypes, including three varieties ('MO4301M', 'Dwight', and 'Pana') and two plant introductions (PI398223 and PI567201A) were planted in four row wide passes ( $0.76 \mathrm{~m}$ between rows) along the entire length (north-south orientation) of the field.

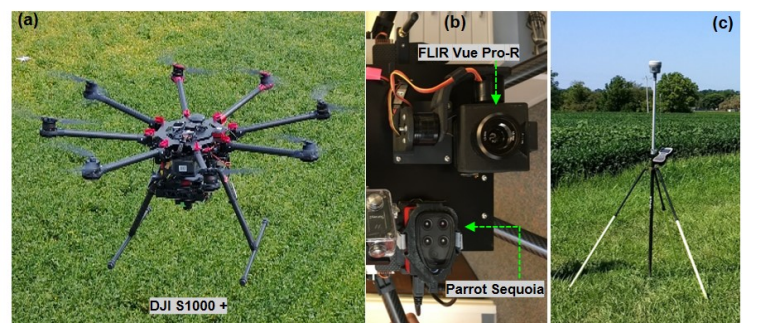

Figure 2. a) DJI S1000+ UAV platform with b) Parrot Sequoia multispectral camera and FLIR Vue ProR thermal imager and c) Trimble R8 GNNS surveying system.

\subsection{Data}

UAV data was collected using a DJI S1000+ (DJI Technology Co., Shenzhen, China) octocopter platform intergrated with a Pixhawk 2.1 (Hex Technology Limited, Xiamen, China) autopilot enabling custom mission planning and user-defined waypoint operations (Figure 2a). A custom multi-sensor payload tray was designed for the $\mathrm{S} 1000+$ platform which held the multispectral (Parrot Sequoia) and thermal (FLIR 
Vue Pro R) sensors utilized for UAV data collection in this study. The Parrot Sequoia is a high-resolution multispectral camera consisting of four 1.2 MP global shutter narrowband spectral cameras that image in the green $(550 \mathrm{~nm})$, red $(660$ $\mathrm{nm})$, red-edge $(735 \mathrm{~nm})$ and near infrared $(790 \mathrm{~nm})$ spectral bands, in addition to a 16 MP rolling shutter RGB camera (Figure 2b). The FLIR Vue Pro R 640 model is comprised of a $13 \mathrm{~mm}$ lens with a $30 \mathrm{~Hz}$ frame rate to record temperature measurements in the $7.5-13.5 \mathrm{~m}$ spectrum range with a +/$5 \mathrm{C}$ measurement accuracy (Figure 2b). Data collection flights were planned using an open-source ground-station controller, Mission Planner (ArduPilot), and were designed using a striping pattern that optimizes photogrammetric data collection. Multispectral and thermal UAV data collection flights were conducted on two dates during the same growing season. One flight was conducted on 20 July 2017 and a series of flights for diurnal analysis were conducted on 4 August 2017 at 0845 , 1045, 1230, 1435, and 1655. All data collection flights utilized the same planned mission parameters and pattern.

WorldView-3 (WV3) (Digital Globe Inc.) VNIR and SWIR imagery were tasked for 16 July 2017 and 22 July 2017 to coincide with UAV and ground truth data collection on 20 June 2017. WV3 is a high resolution multi-payload satellite which provides $31 \mathrm{~cm}$ panchromatic resolution, $1.24 \mathrm{~m}$ multispectral (VNIR) resolution and $7.5 \mathrm{~m}$ SWIR resolution. Eight VNIR bands are imaged in the coastal $(400450 \mathrm{~nm})$, blue $(450510$ $\mathrm{nm})$, green $(510580 \mathrm{~nm})$, yellow $(585625 \mathrm{~nm})$, red $(630690$ $\mathrm{nm})$, red edge (705745 nm), NIR1 (770895 nm) and NIR2 $(8601040 \mathrm{~nm})$ wavelength regions. Eight SWIR bands are imaged in SWIR-1 (11841235 nm), SWIR-2 (15461598 nm), SWIR-3 (16361686 nm), SWIR-4 (17021759 nm), SWIR-5 (21372191 nm), SWIR-6 (21742232 nm), SWIR-7 (22282292 $\mathrm{nm})$ and SWIR-8 (22852373 $\mathrm{nm})$ wavelength regions.

In addition to remote sensing imagery collection, the Trimble R8 Global Navigation Satellite System (GNSS) surveying equipment with both an integrated antenna and receiver was used for the real-time kinematic (RTK) GNSS surveying of 5 targeted ground control points (GCPs) in the field (Figure 2c).

\section{METHODS}

\subsection{UAV image processing}

Collections of multispectral images acquired from a UAV integrated Parrot Sequoia camera, and thermal images from the FLIR camera were orthorectified and mosaicked through Pix4Dmapper software package (Pix4D SA, Lausanne, Switzerland). Geographic information of five survey grade high-accuracy GCPs were loaded into the Pix4Dmapper processing workflow, to improve scale and geometry accuracy of the orthomosaics (Maimaitijiang et al., 2019). The radiometric calibration of multispectral imagery was conducted during the Pix4Dmapper processing workflow utilizing the real-time irradiance values captured by the solar irradiance sensor during the flight (Maimaitijiang et al., 2017). Using synchronously measured surface temperature during the UAV flight, and corresponding thermal imagery values, empirical line method based calibration model for FLIR thermal images was established. This model is able to convert at-sensor radiometric temperature of FLIR thermal images to surface temperature in degrees Celsius (C), and accounts for emissivity and atmospheric impact to some extent (Berni et al., 2009). The details of the thermal imagery calibration procedures was outlined in (Sagan et al., 2019).
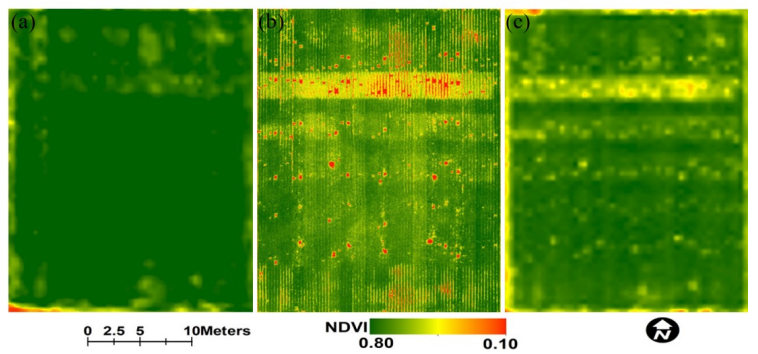

Figure 3. Spatiotemporal change of NDVI. Spatial distribution of NDVI calculated from WV3 satellite data acquired on 16 July 2017 (a), NDVI calculated from UAV data collected on 20 July 2017 (b), and (c) shows NDVI from WV3 data collected on 22 July 2017. The figures show the NDVI values change from north to south of the field from $0.3 \mathrm{~m}$ rooting depth to $0.45 \mathrm{~m}, 0.6 \mathrm{~m}$, and 0.75 $\mathrm{m}$ rooting depths divergence. It is worth to note that the lowest NDVI spots distributed over the images represent locations of destructive biomass sampling

\subsection{Satellite image processing}

Radiometric calibration was carried out for WV3 imagery to convert the raw digital number (DN) to Top of the Atmospheric (TOA) radiance using ENVI 5.4.1 software (Harris Visual Information Solutions, Boulder, CO, USA). Then atmospheric correction was conducted using Fast Line-of-Sight Atmospheric Analysis of Spectral Hypercubes (FLAASH) algorithm embedded in the ENVI software package, followed by the conversion of the WV3 image radiance values to surface reflectance (Sidike et al., 2019). Geometric calibration was not applied because of the flat topography of the study site. Finally, high resolution WV3 multispectral reflectance images were created using $0.3 \mathrm{~m}$ spatial resolution panchromatic data based on Gramm-Schmidt Pan Sharpening tool of ENVI software (Hartling et al., 2019). UAV orthomosaics and satellite reflectance images were co-registered and geo-referenced to WGS 1984 UTM Zone $15 \mathrm{~N}$ generating a unified imagery dataset using ArcGIS 10.4 software for further analysis.

\subsection{Statistical analysis}

Commonly used vegetation indices (VIs) such as NDVI (Normalized difference vegetation index), GNDVI (Green normalized difference vegetation index) and NDRE (Normalized difference red-edge index) were calculated using UAV multispectral and WV3 imagery in order to monitor the temporal and diurnal change of crop water stress. Plot-level mean canopy temperature and VIs were extracted using zonal statistics tool of ArcGIS 10.4 software. To compare and evaluate the impact of different water treatment, one-way analysis of variance (ANOVA) with an honest significant difference (HSD) Tukey test $(=0.05)$, was implemented to plot-level canopy temperature and VIs values with IBM SPSS software (version 24, IBM Corp., Armonk, NY, US).

\section{RESULTS AND DISCUSSION}

\subsection{Temporal evolution of stress}

Multitemporal measurement of three different VIs (NDVI, NDRE, GNDVI) that are sensitive to plant traits, such as 


\begin{tabular}{|c|c|c|c|c|c|c|c|c|}
\hline Sensors & \multicolumn{2}{|c|}{ Green $(\mathrm{nm})$} & \multicolumn{2}{|c|}{ Red $(\mathrm{nm})$} & \multicolumn{2}{|c|}{ Red Edge (nm) } & \multicolumn{2}{|c|}{ NIR (nm) } \\
\hline $\begin{array}{c}\text { UAV } \\
\text { Multispectral }\end{array}$ & $\begin{array}{c}\text { Central } \\
\text { wavelength }\end{array}$ & $\begin{array}{l}\text { Band } \\
\text { width }\end{array}$ & $\begin{array}{c}\text { Central } \\
\text { wavelength }\end{array}$ & $\begin{array}{l}\text { Band } \\
\text { width }\end{array}$ & $\begin{array}{c}\text { Central } \\
\text { wavelength }\end{array}$ & $\begin{array}{l}\text { Band } \\
\text { width }\end{array}$ & $\begin{array}{c}\text { Central } \\
\text { wavelength }\end{array}$ & $\begin{array}{l}\text { Band } \\
\text { width }\end{array}$ \\
\hline & 550 & 40 & 660 & 40 & 735 & 10 & 790 & 40 \\
\hline WV3 & \multicolumn{2}{|c|}{$510-580$} & \multicolumn{2}{|c|}{$630-690$} & \multicolumn{2}{|c|}{$705-745$} & \multicolumn{2}{|c|}{$770-895$} \\
\hline
\end{tabular}

Table 1. Band information comparison of WV3 satellite and UAV multispectral sensors.

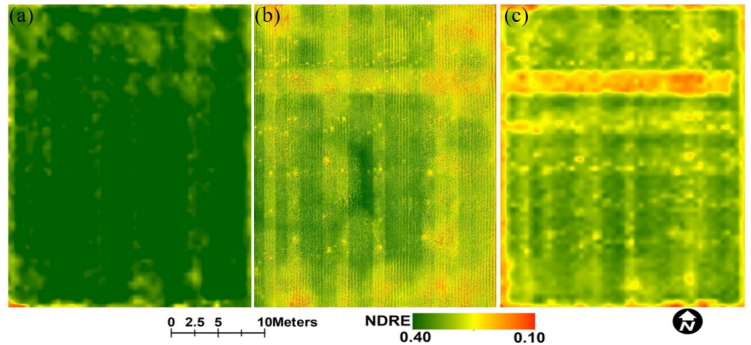

Figure 4. Spatiotemporal change of NDRE. Spatial distribution of NDRE calculated from WV3 satellite data acquired on 16 July 2017 (a), NDRE calculated from UAV data collected on 20 July 2017 (b), and (c) shows NDVI from WV3 data collected on 22 July 2017. The figures show the NDRE values change from north to south of the field from $0.3 \mathrm{~m}$ rooting depth to $0.45 \mathrm{~m}, 0.6 \mathrm{~m}$, and $0.75 \mathrm{~m}$ rooting depths divergence

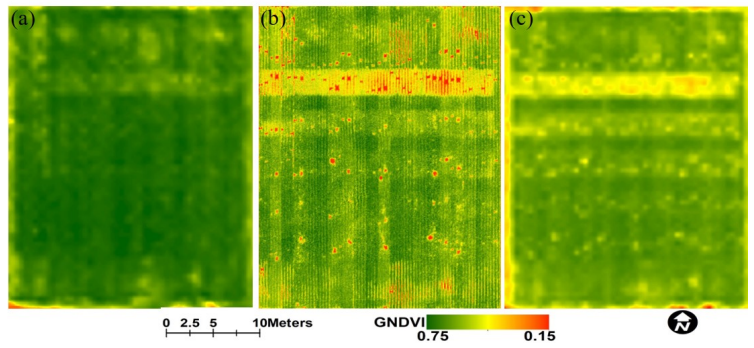

Figure 5. Spatiotemporal change of GNDVI. Spatial distribution of GNDVI calculated from WV3 satellite data acquired on 16 July 2017 (a), GNDVI calculated from UAV data collected on 20 July 2017 (b), and (c) shows GNDVI from WV3 data collected on 22 July 2017. The figures show the GNDVI values change from north to south of the field from $0.3 \mathrm{~m}$ rooting depth to $0.45 \mathrm{~m}, 0.6$ $\mathrm{m}$, and $0.75 \mathrm{~m}$ rooting depths divergence

chlorophyll, biomass and leaf area index (Gitelson et al., 1996), were investigated as shown in Figures 3-5. The core drought simulation experiment was conducted from 16 July 2017 (a day followed a small amount rain, representing no water stress) to 22 July 2017 when shallower rooting depths were exposed to significant stress. With increasing temperature and no rain period as shown in Figure 6, all treatments except 0.9 m rooting depth were exposed to mild ( $0.75 \mathrm{~m}$ rooting depth) to severe water stress $(0.3 \mathrm{~m}$ rooting depth). The corresponding data were obtained by collecting WV3 satellite imagery on 16 July (no water stress as light rain were observed prior days) and 22 July 2017 (stress was advanced to most of the treatments), and UAV-data on 20 July 2017 (mild stress was developed). The temporal changes of NDVI (Figure 3) in the satellite (Figure 3(a) and (c)) and UAV (Figure 3(c)) platforms indicated the capacity for photosynthesis. The lower NDVI on 20 July can be associated with local temperature variations (Figures 6 and

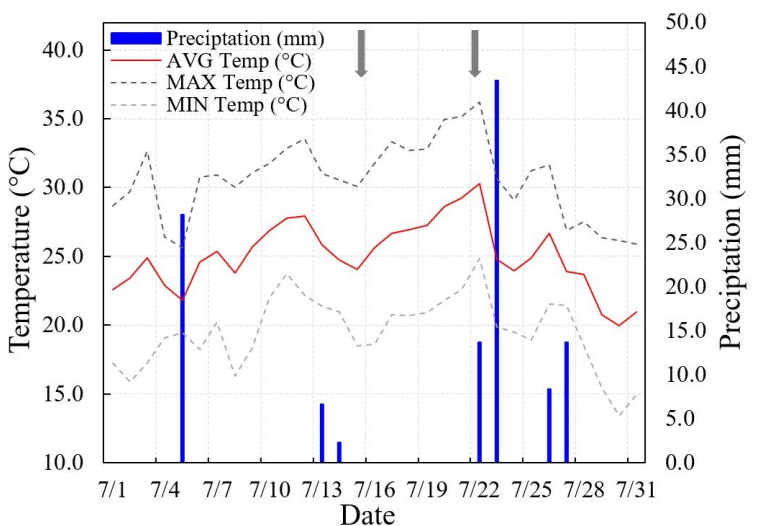

Figure 6. Daily average of temperature and precipitation during core stress experiment conducted in July 2017.

There was no rain during the one week stress experiment starting from 16 July to 22 July 2017, and higher air temperature during the experiment enabled effective simulation of early stress that were captured by

$\mathrm{UAV} /$ satellite temporal data fusion. Arrows indicate the start/end dates of stress development

8) where higher temperature regions in the images have the corresponding lower NDVI value in general. A similar trend is also observed from NDRE (Figure 4) and GNDVI (Figure 5) images. Compared to NDVI, NDRE and GNDVI have demonstrated better dynamic variation in satellite imagery to represent canopy cover status in the field over time. This is likely attributed to the higher sensitivity of NDRE and GNDVI to biochemical variables of plants such as chlorophyll and $\mathrm{N}$ concentration which avoids early saturation of NDVI (Cammarano et al., 2014, Eitel et al., 2011, Gitelson et al., 1996). In detail, more $N$ and chlorophyll stress are detected on 22 June from WV3 imagery as well as 20 June from UAV imagery.

Figure 7 depicts temporal changes of canopy NDVI, NDRE and GNDVI for different water availability imposed by the five incrementally increasing rooting depth treatments. As expected, more limited on rooting depth (i.e., $0.3 \mathrm{~m}$ excavated channels), which constrains plant available soil moisture, lowered values of NDVI, NDRE and GNDVI. Furthermore, the collection date with the highest temperature (on 22 July; Figure 6) resulted in the lowest values of NDRE and GNDVI, which corresponds to the reduction of biochemical variables such as chlorophyll content and exposed leaf area as leaf temperature increases (Maimaitijiang et al., 2017). It is worth mentioning that NDVI did not decrease on 22 July compared to 20 July (Figure 7 (a)). The reasons could be two-fold: 1) The data collection platform is different. Data from 20 July was acquired by UAV multispectral sensor (PARROT SEQUOIA) whereas the WV3 satellite sensor was used in 22 July, suggesting that different sensor properties such as band width (Table 1) may cause inconsistent results. 2) NDVI is affected by soil background reflectance at low canopy cover 

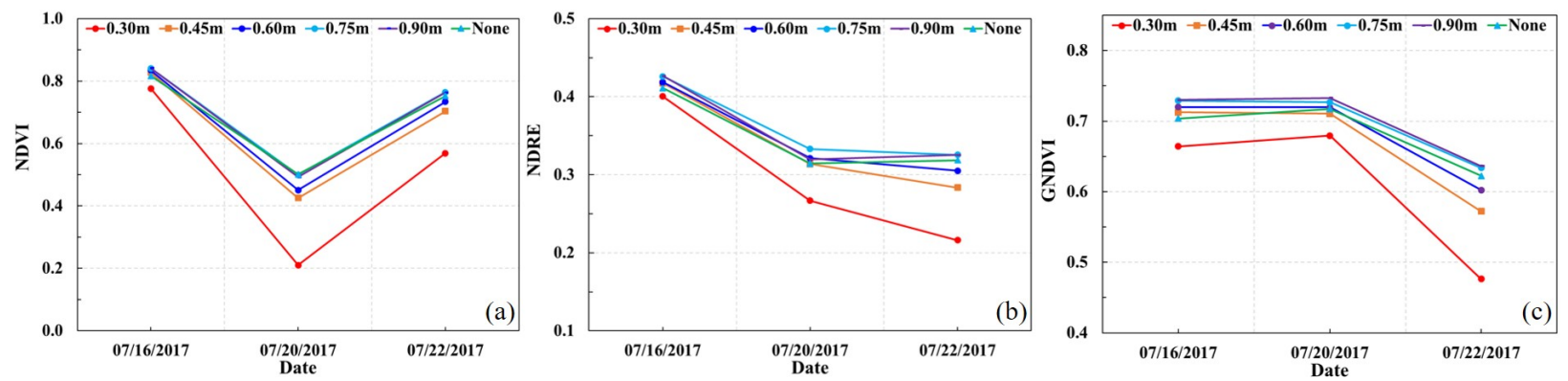

Figure 7. Temporal change of canopy NDVI, NDRE and GNDVI with different water treatment during the experiment. The indices were averaged over each rooting depth after soil removal

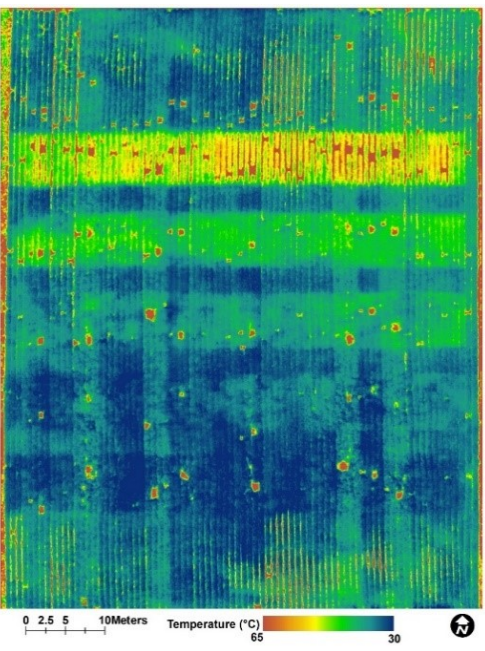

Figure 8. Spatial distribution of canopy temperature derived from UAV thermal imagery on 20 July 2017 , which shows stress development from north to south of the field from $0.3 \mathrm{~m}$ rooting depth to $0.45 \mathrm{~m}, 0.6 \mathrm{~m}$, and $0.75 \mathrm{~m}$ rooting depths. It is worth to note that regular pattern of high temperature spots distributed over the image represent locations of destructive biomass sampling

(Rondeaux et al., 1996), whereas more soil background can be captured by low-altitude UAV data compared to WV3 satellite imagery that contains several pixel-mixing issues due to lower spatial resolution. This could potentially lead to uneven NDVI values generated from two different imaging platforms.

The performance of NDVI, NDRE and GNDVI retrieved from WV3 and UAV platform was tested for detecting the effects of rooting depth treatments. Statistically significant differences in NDVI, NDRE and GNDVI were observed between rooting depth treatments for all three dates (Table 2). These indices were highly and constantly sensitive to $0.3 \mathrm{~m}, 0.45 \mathrm{~m}$ and 0.60 $\mathrm{m}$ treatments and these treatments can be easily distinguished from other treatments with high confidence. NDVI and GNDVI between $0.75 \mathrm{~m}, 0.90 \mathrm{~m}$ and control treatments were statistically significant on all dates, whereas NDRE was only indicated significant differences between these treatments on 22 July 2017.

\subsection{Diurnal changes}

Figure 9 shows a comparative view of the diurnal temperature changes. The canopy temperature, which ranged from $15^{\circ} \mathrm{C}$ to $55^{\circ} \mathrm{C}$ was extracted from the FLIR images acquired during five flights that were conducted at approximately two-hour intervals starting from 8:45 AM to 16:55 PM on 04 August 2017 (Figure 9). Canopy temperature gradually increases from morning to noon and then decreases slightly by $16: 55$ PM. A distinct visible area of higher temperature (red spot) is evident in a horizontal channel of the north region in the field, where the rooting depth was restricted to $0.3 \mathrm{~m}$ depth (Rondeaux et al., 1996, Sagan et al., 2019). This phenomenon is more clearly observed from the NDVI map (Figure 10) where lower NDVI values are concentrated on the regions that have higher temperature. This indicates the impact of water stress on the photosynthetic performance of the plant because water stress created by limiting rooting depth can cause stomata closure and accordingly lead to canopy temperature increase (Maimaitijiang et al., 2017). Figure 11 exhibits the corresponding NDRE (Normalized Difference Red Edge) images generated from multispectral imagery captured by a Parrot Sequoia sensor. NDRE showed better response of water stress (i.e., vertical red channels in Figure 11) to the different genotypes than NDVI. This can be attributed to NDRE employing red-edge reflectance which is more sensitive to the $\mathrm{N}$ content and Chl $\mathrm{a}+\mathrm{b}$ (Cammarano et al., 2014) than red reflectance and varied in different genotypes.

Figure 12 shows the impact of different rooting treatment on canopy temperature, NDVI and NDRE over time-of-day. In details, Figure 12(a) presents the influence of five different rooting depth treatments on diurnal canopy temperature. It is evident that the canopy temperature increased with solar angle changes, or where more solar radiation was absorbed. Additionally, the rooting depth treatment of $0.3 \mathrm{~m}$ always exhibited higher temperature regardless of time-of-day compared to the other treatments where less temperature difference was found. The values of NDVI (Fig.12 (b)) and NDRE (Fig.12 (c)) shows relatively less fluctuation over the time-of-day, while the rooting depth treatment of $0.3 \mathrm{~m}$ generally produced the lowest values. Particularly, NDRE values showed more obvious divergence between the $0.3 \mathrm{~m}$ depth treatment and the other treatments. This result is consistent with lower plant available soil moisture in with restricted rooting depth leading to more water deficit stress in plants.

Differences in canopy temperature between rooting depth treatments were statistically significant throughout the day (Table 3). A pairwise comparison of the treatments (all the Tukeys HSD results not shown) revealed that the $0.3 \mathrm{~m}$ treatment had significantly higher temperatures than any other treatments at 8:45 am, 12:30 pm and 14:35 pm. The $0.45 \mathrm{~m}$ treatment also showed higher canopy temperature compared to other treatments; however, the differences were only significant 


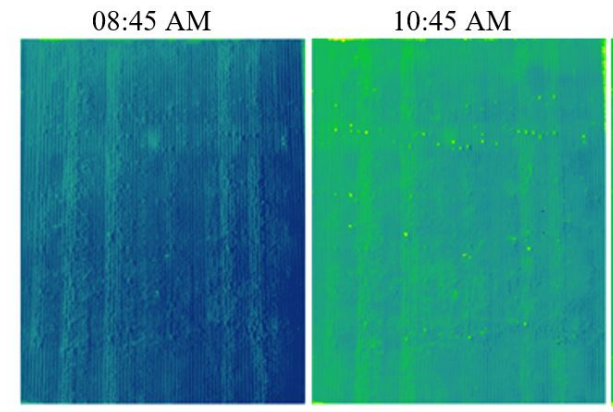

$\stackrel{0}{225} 5,10$ Meters
$12: 30 \mathrm{PM}$

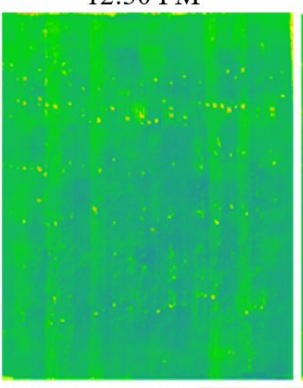

Temperature $\left({ }^{\circ} \mathrm{C}\right)$
$14: 35 \mathrm{PM}$

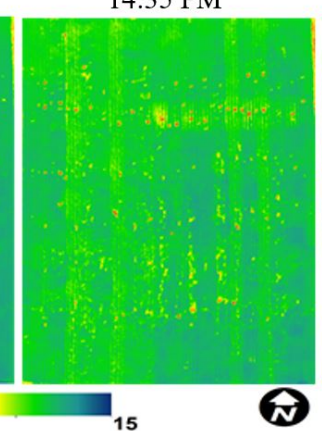

16:55 PM

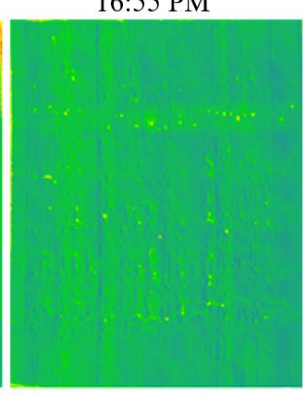

Figure 9. Visualization of spatial and diurnal change of canopy temperature, which indicates stress development and recovery from north to south of the field corresponding to from $0.3 \mathrm{~m}$ rooting depth to $0.45 \mathrm{~m}, 0.6 \mathrm{~m}$, and $0.75 \mathrm{~m}$ rooting depths divergence
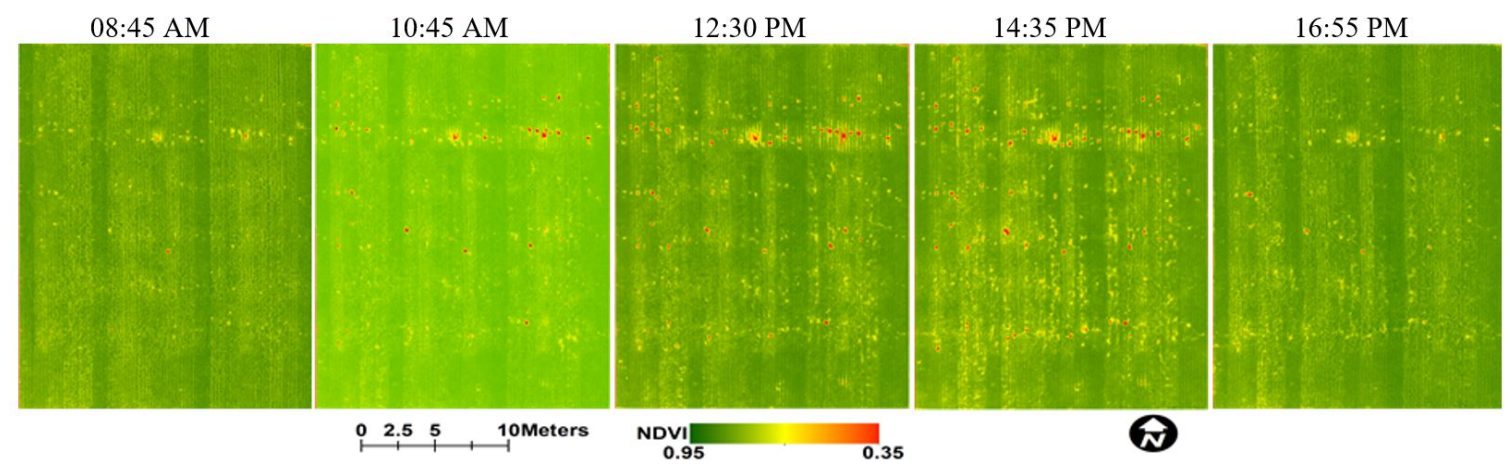

Figure 10. Visualization of spatial and diurnal change of NDVI, which indicates stress development and recovery from north to south of the field from $0.3 \mathrm{~m}$ rooting depth to $0.45 \mathrm{~m}, 0.6 \mathrm{~m}$, and $0.75 \mathrm{~m}$ rooting depths divergence

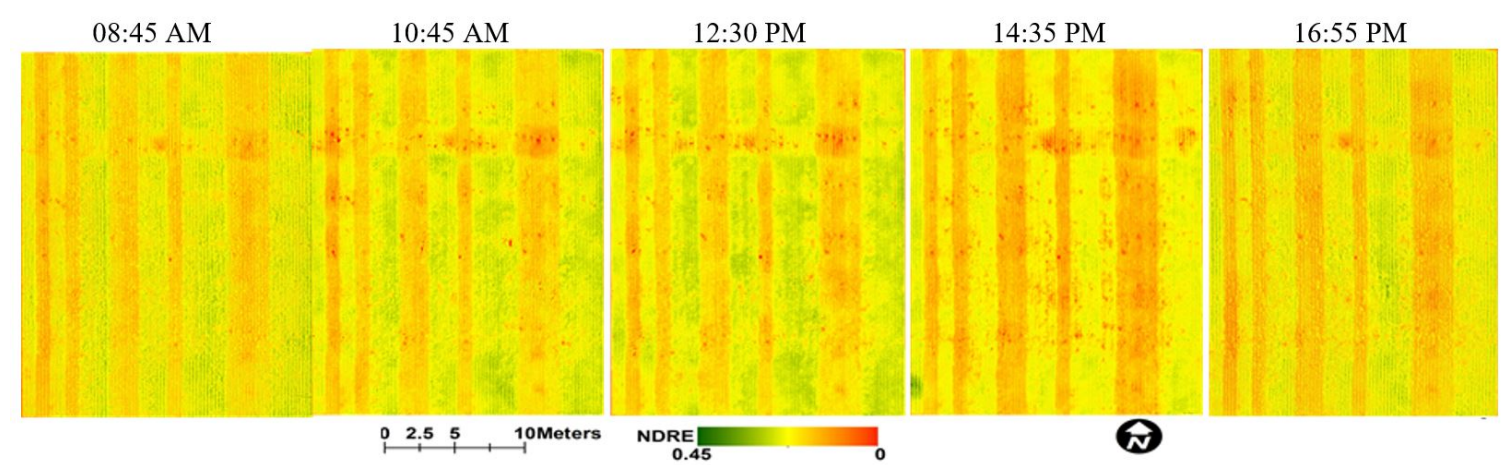

Figure 11. Visualization of spatial and diurnal change of NDRE, which indicates stress development and recovery from north to south of the field from $0.3 \mathrm{~m}$ rooting depth to $0.45 \mathrm{~m}, 0.6 \mathrm{~m}$, and $0.75 \mathrm{~m}$ rooting depths divergence
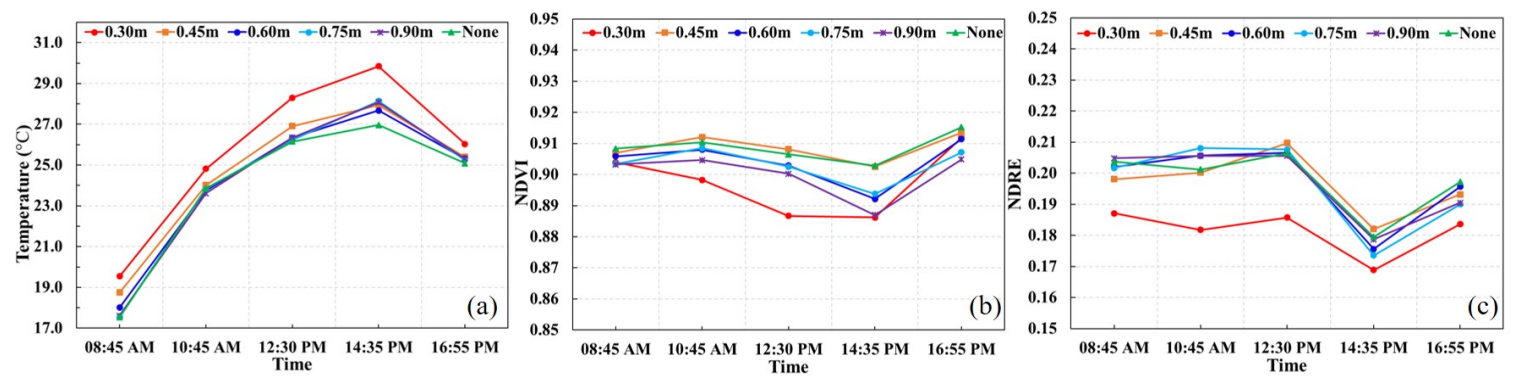

Figure 12. Diurnal change of canopy temperature, NDVI and NDRE with different water treatment and time of the day

with $0.6 \mathrm{~m}$ and $0.9 \mathrm{~m}$ treatments in the mid-morning (10:45 am), and with $0.75 \mathrm{~m}$ and control in the late afternoon $(16: 55$ pm). Average NDVI of each rooting depth was significantly different in three UAV diurnal data collections at 10:45 am, 


\begin{tabular}{c|c|c|c|c|c|c|c|c|c}
\hline & \multicolumn{3}{|c|}{$07 / 16 / 2017$} & \multicolumn{3}{c|}{$07 / 20 / 2017$} & \multicolumn{3}{c}{$07 / 22 / 2017$} \\
\cline { 2 - 9 } & NDVI & NDRE & GNDVI & NDVI & NDRE & GNDVI & NDVI & NDRE & GNDVI \\
\hline F-static & 53 & 6.5 & 58 & 83 & 15 & 38 & 257 & 141 & 317 \\
\hline p-value & \multicolumn{8}{|c}{$<.01$} \\
\hline
\end{tabular}

Table 2. ANOVA results of different rooting depth treatments based temporal WV3 and UAV images.

\begin{tabular}{|c|c|c|c|c|c|c|c|c|c|c|c|c|c|c|c|}
\hline & \multicolumn{3}{|c|}{$08: 45 \mathrm{AM}$} & \multicolumn{3}{|c|}{ 10:45 AM } & \multicolumn{3}{|c|}{$12: 30 \mathrm{PM}$} & \multicolumn{3}{|c|}{$14: 35 \mathrm{PM}$} & \multicolumn{3}{|c|}{ 16:55 PM } \\
\hline & $\mathrm{T}$ & NDVI & NDRE & $\mathrm{T}$ & NDVI & NDRE & $\mathrm{T}$ & NDVI & NDRE & $\mathrm{T}$ & NDVI & NDRE & $\mathrm{T}$ & NDVI & NDRE \\
\hline F-static & 8.4 & 1.3 & 1.0 & 2.6 & 4.0 & 1.7 & 13 & 5.9 & 1.3 & 13 & 5.1 & .41 & 3.3 & 2.4 & .45 \\
\hline p-value & .00 & .30 & . 44 & 0.29 & .00 & .15 & .00 & .00 & .29 & .00 & .00 & 0.84 & .01 & .05 & .82 \\
\hline
\end{tabular}

Table 3. ANOVA results of different root depth treatments based on diurnal UAV images.

12:30 pm and 14:35 pm. Furthermore, the $0.3 \mathrm{~m}$ treatment had significantly lower NDVI values compared to other treatments, which is especially true for NDVI values at $12: 30 \mathrm{pm}$. On the contrary, the rooting depth treatments had no significant effect on NDRE.

\section{CONCLUSION}

This paper presented a concept of temporal fusion within the framework of virtual constellation of UAV and satellite remote sensing data for crop phenotyping and early stress detection. Crop responses to multi-day and diurnal water stress were examined using VNIR and thermal images. Statistical methods were used to quantify the difference in early stress development among different rooting depth treatments.

UAV remote sensing is a critical tool for filling the temporal gap in satellite data for crop monitoring. By capturing the water stress progression, UAV integrated sensors combined with satellite data may characterize the stress development preemptively, enabling proactive field management and irrigation scheduling for improved crop yields.

The thermal domain is highly effective in monitoring diurnal changes in temperature induced by different rooting depth treatments, whereas the multispectral indices were less affected by the treatments. Furthermore, NDVI, NDRE, and GNDVI are potential indices to be used from UAV or/and satellite platforms for estimation of moderate to severe water stress.

Due to the differences in spatial and spectral resolutions, discrepancies between UAV- and satellite-based platforms were found for commonly used spectral indices (i.e., NDVI), which might be attributed to soil exposure from pixel and atmospheric effects pertinent to satellite data. This emphasizes the value of UAV data in translating field-level crop models to satellite data for accurate monitoring of agricultural landscapes at regional or global scales. Future research should focus on UAV/satellite virtual constellation for developing harmonized data at field and satellite scales.

\section{ACKNOWLEDGEMENTS}

This work was supported in part by the National Science Foundation (IIA-1355406 and IIA-1430427), and in part by the National Aeronautics and Space Administration (NNX15AK03H).

\section{REFERENCES}

Anderson, M.C., Allen, R.G., Morse, A., Kustas, W. P, 2012. Use of Landsat thermal imagery in monitoring evapotranspiration and managing water resources. Remote Sensing of Environment, 122, 50-65.

Berni, J.A.J., Zarco-Tejada, P.J., Suárez, L., Fereres, E., 2009. Thermal and narrowband multispectral remote sensing for vegetation monitoring from an unmanned aerial vehicle. IEEE Transactions on Geoscience and Remote Sensing, 47, 722-738.

Cammarano, D., Fitzgerald, G.J., Casa, R., Basso, B., 2014. Assessing the Robustness of Vegetation Indices to Estimate Wheat $\mathrm{N}$ in Mediterranean Environments. Remote Sensing, 6, 2827-2844.

Chakraborty, A., Seshasai, M.V.R., Dadhwal, V.K., 2016. Assessing crop water stress during late kharif season using Normalized Diurnal Difference Vegetation Water Content (nddVWC) of Advanced Microwave Scanning Radiometer-Earth Observing System (AMSR-E). Natural Hazards, 84, 533-549.

Damm, A., Paul-Limoges, E., Haghighi, E., Simmer, C., Morsdorf, F., Schneider, F.D., van der Tol, C., Migliavacca, M., Rascher, U., 2018. Remote sensing of plant-water relations: An overview and future perspectives. Journal of plant physiology, 227, 3-19.

Eitel, J.U.H., Vierling, L.A., Litvak, M.E., Long, D.S., Schulthess, U., Ager, A.A., Krofcheck, D.J., Stoscheck, L., 2011. Broadband, red-edge information from satellites improves early stress detection in a New Mexico conifer woodland. Remote Sensing of Environment, 115, 3640 - 3646.

Ghulam, A., Li, Z.L., Qin, Q.M., Yimit, H., Wang, J., 2008. Estimating crop water stress with ETM + NIR and SWIR data. Agricultural and Forest Meteorology, 148, 1679-1695.

Gitelson, A.A., Kaufman, Y.J., Merzlyak, M.N., 1996. Use of a green channel in remote sensing of global vegetation from EOS-MODIS. Remote Sensing of Environment, 58, 289 - 298.

Han, M., Zhang, H.H., DeJonge, K.C., Comas, L.H., Trout, T.J., 2016. Estimating maize water stress by standard deviation of canopy temperature in thermal imagery. Agricultural water management, 177, 400-409.

Hartling, S., Sagan, V., Sidike, P., Maimaitijiang, M., Carron, J., 2019. Urban Tree Species Classification Using a WorldView-2/3 and LiDAR Data Fusion Approach and Deep Learning. Sensors, 19, 1284.

Kogan, F.N., 1995. Application of vegetation index and brightness temperature for drought detection. Advances in space research, 15, 91-100. 
Maimaitijiang, M., Ghulam, A., Sidike, P., Hartling, S., Maimaitiyiming, M., Peterson, K., Shavers, E., Fishman, J., Peterson, J., Kadam, S., Burken, J., Fritschi, F.B., 2017. Unmanned aerial system (UAS)-based phenotyping of soybean using multi-sensor data fusion and extreme learning machine. ISPRS Journal of Photogrammetry and Remote Sensing, 134, 43-58.

Maimaitijiang, M., Sagan, V., Sidike, P., Maimaitiyiming, M., Hartling, S., Peterson, K.T., Maw, M.J.W., Shakoor, N., Mockler, T., Fritschi, F.B., 2019. Vegetation Index Weighted Canopy Volume Model (CVMVI) for soybean biomass estimation from Unmanned Aerial System-based RGB imagery. ISPRS Journal of Photogrammetry and Remote Sensing, 151, 27-41.

Rondeaux, G., Steven, M., Baret, F., 1996. Optimization of soil-adjusted vegetation indices. Remote Sensing of Environment, 55, 95 - 107.

Sagan, V., Maimaitijiang, M., Sidike, P.and Eblimit, K., Peterson, K.T, Hartling, S., Esposito, F., Khanal, K., Newcomb, M., Pauli, D., Ward, R., Fritschi, F., Shakoor, N., Mockler, T., 2019. UAV-based high resolution thermal imaging for vegetation monitoring, and plant phenotyping using ici 8640 p, flir vue pro r 640, and thermomap cameras. Remote Sensing, 11,330 .

Seguin, B., Lagouarde, J.P., Savane, M., 1991. The assessment of regional crop water conditions from meteorological satellite thermal infrared data. Remote sensing of environment, 35, $141-148$.

Sidike, P., Sagan, V., Maimaitijiang, M., Maimaitiyiming, M., Shakoor, N., Burken, J., Mockler, T., Fritschi, F.B., 2019. dPEN: deep Progressively Expanded Network for mapping heterogeneous agricultural landscape using WorldView-3 satellite imagery. Remote Sensing of Environment, 221, 756-772.

Steele-Dunne, S.C., McNairn, H., Monsivais-Huertero, A., Judge, J., Li, P.W., Papathanassiou, K., 2017. Radar remote sensing of agricultural canopies: A review. IEEE Journal of Selected Topics in Applied Earth Observations and Remote Sensing, 10, 2249-2273. 